Originally published as:

Dieckhoff, B., Kessler, B., Jobst, D., Kues, W., Petersen, B., Pfeifer, A., Kurth, R., Niemann, H., Wolf, E., Denner, J.

Distribution and expression of porcine endogenous retroviruses in multi-transgenic pigs generated for xenotransplantation

(2009) Xenotransplantation, 16 (2), pp. 64-73.

DOI: 10.1111/j.1399-3089.2009.00515.x

The definitive version is available at www3.interscience.wiley.com 


\title{
Distribution and expression of porcine endogenous retroviruses in multi-transgenic pigs generated for xenotransplantation
}

\author{
Britta Dieckhoff, ${ }^{1}$ Barbara Kessler, ${ }^{2}$ Danny Jobst,${ }^{1}$ Wilfried Kues, ${ }^{3}$ Björn Petersen, ${ }^{3}$ Alexander Pfeifer, ${ }^{4}$ \\ Reinhard Kurth, ${ }^{1}$ Heiner Niemann, ${ }^{3}$ Eckhard Wolf ${ }^{2}$ and Joachim Denner ${ }^{1}$ \\ ${ }^{1}$ Robert Koch-Institute, Berlin \\ ${ }^{2}$ Chair for Molecular Animal Breeding and Biotechnology and Laboratory for Functional Genome Analysis (LAFUGA), Gene \\ Center, LMU Munich \\ ${ }^{3}$ Institute of Farm Animal Genetics, Friedrich-Loeffler-Institute (FLI), Mariensee \\ ${ }^{4}$ Institute of Pharmacology and Toxicology, University of Bonn, Bonn, Germany
}

Background: Multi-transgenic pigs produced for use in xenotransplantation have to be screened for the presence and expression of porcine endogenous retroviruses (PERV) to select animals with low PERV load. The production of transgenic pigs may also be associated with the integration of the transgene adjacent to or into the locus of a PERV provirus, potentially leading to an enhanced virus expression.

Methods: Non-transgenic animals, single-transgenic, and multitransgenic pigs were screened for the presence of PERV-A, $-B$, and $-C$ and recombinant PERV-A/C using polymerase chain reaction (PCR). $P E R V$ expression was determined by real time reverse transcriptase-PCR. An assay based on the activation of PERV in peripheral blood mononuclear cells by mitogens was used to discriminate between low and high PERV producer animals.

Results: All animals carried PERV-A and -B. A total of 176 from 181 (97.2\%) animals carried PERV-C in the germ line and 18 from 64 animals carried PERV-A/C in the genome of lymphoid cells but not in the germ line. The expression of PERV was very low in all animals and not different between transgenic pigs and non-transgenic animals. PERV expression differed between various pig lines. The highest expression was found in mini-pigs and crossing other pig lines with mini-pigs resulted in increased PERV expression in the progeny. However, expression of viral proteins and particle release were not observed in all transgenic animals.

Conclusions: No evidence for elevated PERV expression in (multi-) transgenic pigs was observed. Differences in PERV expression correlated with the genetic background of the animals, not with the specific transgene. Mini-pigs consistently had the highest level of PERV expression and animals with a mini-pig background had a higher level of expression compared with animals without mini-pig background. 


\section{Introduction}

Xenotransplantation of cells, tissues, and organs from pigs to human patients is a promising solution for the acute shortage of human organs in allotransplantation. For several reasons, pigs are the most favored donor animals for xenotransplants [1]. However, there are three major obstacles to successful xenotransplantation: first, the immunological rejection, second, the physiological incompatibility, and third, the risk of zoonoses [2]. Among pig microorganisms that may be transmitted and are currently known to induce zoonoses, porcine endogenous retroviruses (PERV) are thought to represent the highest risk for human recipients [3]. PERVs are present in the genome of all pigs [4-6] and are released from normal pig cells [7-9], and at least PERV-A, PERV-B, and recombinants between PERV-A and PERV-C (PERV-A/C) have been shown to replicate in human cells in vitro, while PERV$C$ is restricted to porcine cells [4,5,10-12]. In order to minimize or avoid transmission of PERV, pigs designed for use in xenotransplantation have to be screened for the presence of proviruses as well as for expression of PERV. We have developed an assay that is based on the ability of mitogens to increase PERV expression in peripheral blood mononuclear cells (PBMCs) $[8,9]$. The use of this assay revealed differences in the expression and release of PERV depending on the pig breed. Differences in PERV expression were also observed between animals of the same breed $[8,9]$.

Recently, recombinant PERV-A/Cs were discovered and de novo integrated proviruses of such recombinants were found in spleen cells of miniature pigs and melanoma bearing Munich miniature pigs [10,13-16], but not in the germ line of these animals. PERV-A/Cs represent a special risk for xenotransplantation because these recombinant viruses may infect human cells and increase their replication competence when passaged on human cells $[10,17,18]$. The increased titer during passage on human cells was associated with genetic alterations in the PERV-C-derived long terminal repeats of these viruses, increasing the number of nuclear factor-Y transcription factor binding sites [17]. When comparing the replication rate of PERV-A with that of PERV-A/C, replication rate of PERV-A/C was increased and an isoleucine to valine substitution was found at position 140 in the receptor binding domain. Changes in the proline rich region of the envelope protein were also reported [19]. The higher replication capacity of recombinant PERV-A/C may be associated with a higher pathogenicity as it was shown in the case of other retroviruses, e.g., human immunodeficiency virus (HIV) and feline leukemia virus.

Until now, several transgenic pig lines have been produced that express immunomodulatory genes which suppress the hyperacute rejection (HAR) of transplanted porcine tissues and cells (for review see [1]). Usually integration of the foreign gene occurs at random and integration may rarely occur upstream of oncogenes, tumor suppressor genes, and/or proviruses of endogenous retroviruses with the potential for tumor development and/or enhanced expression of endogenous retroviruses. The goal of the present study was to evaluate the presence of PERV variants in pigs carrying one or more transgenes

in comparison with wild-type animals. To reveal whether PERVs are activated in transgenic and multitransgenic pigs, the expression of PERVs in such animals was compared with the level of PERV expression in non-transgenic animals. We also show the genetic distribution of PERV-C and recombinant PERV-A/C in different pig breeds including wild boars. A stringent screening for PERV-C was performed as the presence of PERV-C in the porcine genome allows recombination with PERV-A that may result in high titer PERV-A/C recombinant viruses [17].

\section{Material and methods}

\section{Animals}

Blood and tissue samples from female and male nontransgenic pigs including German Landrace (GL), Duroc (Du), Schwäbisch-Hällisch (SH), German Large White (GLW, Deutsches Edelschwein), Mini-pig (MP) as well as transgenic crossbreds (GL/Du, GL/Pietrain, Du/MP, GLW/Du/MP, GL/Du/MP) were obtained from the large animal facilities of the Chair for Molecular Animal Breeding and Biotechnology, LMU Munich, and from the Institute of Farm Animal Genetics (FLI), Mariensee. Transgenic pigs were produced by pronuclear DNA microinjection, by lentiviral vectors, or by somatic nuclear transfer (SCNT) from transfected cells pronuclear (Table 1). For production of transgenic pigs using pronuclear DNA microinjection or lentiviral vectors, fertilized oocytes (zygotes) were obtained by flushing the oviducts of estrus-synchronized and superovulated gilts that had been inseminated 24 and $36 \mathrm{~h}$ prior 
to slaughter. Embryos were collected and either centrifuged and DNA-microinjected into pronuclei (DNA microinjection) [20] or a lentiviral vector carrying the transgene was injected directly under the zona pellucida (lentiviral transgenesis) [21]. On the same day, embryo transfer was performed endoscopically into the oviduct of estrus synchronized recipient gilts, according to the method described by Besenfelder et al. [22]. Transgenic animal production by SCNT was performed as described recently [23]. In addition, 18 wild boars were hunted at different places near Berlin in 2005 and were included in the analysis.

\section{Isolation and mitogen stimulation of porcine PBMCs}

Peripheral blood mononuclear cells were isolated from heparin-treated blood by density gradient separation using Ficoll (PAA Laboratories $\mathrm{GmbH}$, Pasching, Austria). The PBMCs were isolated, washed three times with phosphate-buffered saline, and resuspended in RPMI-1640 medium (Invitrogen, Karlsruhe, Germany) with 10\% fetal calf serum (lot 0898K; Biochrom, Berlin, Germany); 106 cells per well of a 24-well plate were stimulated with $80 \mathrm{lg} / \mathrm{ml}$ phytohemagglutinin (PHA) (Oxoid, Wesel, Germany) for 5 days at 37 C. Control cells were incubated in RPMI culture medium alone. Each experiment was performed in triplicate.

\section{Cell lines}

Porcine endogenous retroviruses-producing porcine kidney cell line PK-15 and the human PERV-A/ Cinfected cell line 293/50 were obtained and cultured as described [17].

\section{Determination of reverse transcriptase activity}

Supernatants of non-stimulated and PHA-stimulated porcine PBMCs were collected after 5 days of incubation and stored at ) 80 _C. Reverse transcriptase (RT) activity was determined using the C-type RT activity Assay (Cavidi, Uppsala, Sweden) according to the manufacturer's protocol.

\section{RNA isolation}

TotalRNAwas isolated from whole blood using the TRI-Reagent_(Sigma, Taufkirchen, Germany) $(0.75 \mathrm{ml}$ per $0.25 \mathrm{ml}$ blood). For isolation of total RNA from tissues, samples were homogenized in liquid nitrogen and resuspended in TRI-Reagent_(Sigma, $1 \mathrm{ml}$ per 50 to $100 \mathrm{mg}$ of tissue). Chloroform (0.2 ml) was added and after centrifugation (12000 g, $15 \mathrm{~min}, 4$ C) total RNA was purified from the aqueous phase using the RNeasy kit (Qiagen, Hilden, Germany), including an oncolumn DNase digestion. For isolation of total RNA from cell cultures, 106 cells were lysed in 650 ॥ RLT__(Qiagen) buffer of the RNeasy kit and processed following the manufacturer's instructions. RNA was stored at )80_C until assayed.

\section{Isolation of DNA from ear biopsies, spleen tissues, whole blood, and PBMCs}

DNA was isolated from ear biopsies using a salt chloroform extraction method. Sixty milligram tissue was incubated in 500 II lysis buffer (160 mm saccharose, $80 \mathrm{~mm}$ EDTA, $100 \mathrm{~mm}$ Tris- $\mathrm{HCl} \mathrm{pH}$ 8.0) (Roth, Karlsruhe, Germany) and 20 II of a proteinase K solution $(20 \mathrm{mg} / \mathrm{ml}$, Invitrogen) at 60 _C over night. After addition of 200 II of a $4.5 \mathrm{~m} \mathrm{NaCl}$ solution and 700 II chloroform/isoamyl alcohō, DNA extraction was performed by centrifugation (10 min, $10000 \mathrm{~g}, 4$ C). The aqueous phase containing genomic DNA was mixed with 700 II isopropanol and after centrifugation and washing with $70 \%(\mathrm{v} / \mathrm{v})$ ethanol, the precipitated DNA was resuspended in $70 \mathrm{II} \mathrm{H2O}$ and stored at )20 _C until assayed. DNA isolation from whole blood or PBMCs was performed using TRI-Reagent BD and TRIReagent, respectively, according to the manufacturer's instructions (Sigma, $0.75 \mathrm{ml}$ per $0.25 \mathrm{ml}$ blood or $1 \mathrm{ml}$ per 106 cells). Wild boar DNA was isolated from spleen tissue using TRI-Reagent. 
Provirus integration was analyzed by PCR, using primers specific for env of all three subtypes, PERV$A,-B$ [24], and PERV-C [5]. For each reaction 100 ng DNA was used. Temperature conditions were as follows: 94 _C, 15 min; 34 cycles (94_C, 30 s; annealing temperature, 30 s; 72 _C, 1 min); 72 _C, 5 min. In addition to the PERVC- specific primers (envCfor, envCrev) [5], a new primer pair was designed and applied (envC.2for, envC.2rev). The presence of PERV-A/C recombinants was investigated by PCR using the following primers: PERV-A env variable region $B$ [13], forward (VRBF) and two different PERV-C primers, transmembrane region (TMR) [13] and PERV-C rev [15]. PCR reactions were performed as described above and with the following temperature conditions: 95 _C, 10 min; 40 cycles (95_C, 30 s; 55 _C, 30 s; 72 _C, 2 min); 72 _C, 10 min.

\section{PERV-C specific real time PCR}

Porcine endogenous retroviruses-C specific real time PCR was performed using the $M \times 4000$ thermocycler (Stratagene, La Jolla, CA, USA), a 5\$-hexachloro-fluorescein phosphoramidite (HEX)labeled probe and primers specific for PERV-C (Table 2).

\section{PERV-specific real time RT-PCR}

Quantitative real time one-step RT-PCR was performed using the Invitrogen SuperScript III platinium system and the MX4000 thermocycler (Stratagene), a 6-carboxy-fluorescein (FAM)-labeled probe (Sigma) and primers specific for PERV gag (Table 2). PERV expression was normalized to the amount of total RNA as well as to the expression of the house-keeping genes, glyceraldehyde 3-phosphate dehydrogenase (GAPDH), b-actin, and hypoxanthine-guanine phosphoribosyltransferase (HPRT). A HEX-labeled probe and primers specific for porcine GAPDH as well as a FAM-labeled probe and primers specific for porcine HPRT (Table 2) were used [25]. For each reaction, $50 \mathrm{ng}$ total RNA and the following temperature conditions were used: 50 _C, 15 min; 95 _C, 2 min; 45 cycles (95_C, 15 s; 54 C, $30 \mathrm{~s}$ ). Expression was normalized to total RNA, porcine GAPDH, and porcine HPRT, respectively, and related to expression in the PERV-producing porcine kidney cell line, PK-15, and in the human PERV-A/C-infected cell line 293/50. Data were analyzed using the DDCT-method [26]. Integrity of RNA was determined by amplifying GAPDH by one-step RT-PCR. False-positive results due to residual DNA were excluded by parallel experiments omitting the RT.

\section{Results}

\section{Genetic distribution of PERV in different pig breeds}

Atotal of 181 pigs of different breeds, including GL, Duroc (Du), SH, GLW (Deutsches Edelschwein), MP as well as crossbreds thereof (GL/Du, GL/ Pietrain, Du/MP, GLW/Du/MP, and GL/Du/MP) were analyzed using primers allowing the discrimination between the PERV subtypes $A, B$, and C. PERV-A and PERV-B proviruses were found in the genome of all animals, only five animals were negative for PERV-C provirus integration. These animals were GL, GL/Pietrain, and Large White (LW)/MP/Du/GL. To exclude false-negative results due to mutations in the primer binding sites, a second primer pair specific for PERV-C was designed (see Materials and methods). Using both primer pairs identical results were obtained. The DNAwas isolated from different sources, such as ear biopsies, whole blood or PBMCs (Table 3). Among the pigs tested were 85 non-transgenic animals. Only one non-transgenic GL animal was PERV-C-negative. Analysis included also 96 transgenic or multitransgenic pigs with different genetic backgrounds. Only four of these were PERV-C-negative, all four had a GL background. All 18 wild boars carried PERV-C proviruses (Table 4). An earlier report had shown absence of PERV-C in a wild boar [27]. There was no correlation between age, weight, or habitat on one hand and PERV-C positivity on the other.

\section{Detection of PERV-A/C in different pig breeds}

Two primer pairs were used to detect recombinant PERV-A/C proviruses. In 18 of 164 investigated animals, PERV-A/C was found in DNA derived from PBMCs, but not when tested in parallel in the 
DNA derived from ear biopsies (Table 5), indicating that the recombinant provirus in the PBMCs represents a de novo integration of a recombinant virus, not yet present in the germ line. As expected, PERV-A/C was not found in PERV-C free animals.

\section{PERV expression in transgenic and non-transgenic pigs}

To study expression of PERV in non-transgenic, transgenic, and multi-transgenic pigs, a PERVspecific one-step RT real time PCR assay was developed allowing to quantify expression of viral full length mRNA. This assay measures quantitatively, expression of PERV-A, PERV-B, and PERV-C. RNA was isolated from whole blood or PBMCs of non-transgenic pigs of the following genetic backgrounds: GL, $\mathrm{Du}, \mathrm{SH}, \mathrm{German}$ white large (GWL), MP as well as Du/GL. Expression of PERV was also studied in PBMCs of transgenic pigs with different hybrid background (MP/Du/ GL, GLW/MP/Du/GL, and GLW/MP/Du) generated by microinjection or lentiviral vectors.

\section{PERV expression was normalized to the amount}

of total RNA and compared with PERV expression in the PERV-producing porcine kidney cell line, PK15, or in the human cell line 293 infected with PERV/50. The level of PERV expression was also normalized to the level of expression of the house-keeping genes, GAPDH and HPRT. PERV expression in PBMCs varied slightly when different pigs of different origins were compared (Table 6). However, there were also differences in PERV expression, when animals of the same litter were compared. Despite subtle differences, PERV expression in primary PBMCs from GL, Du, SH, GWL as well as Du/GL was very low when compared with PERV expression in the cell lines PK-15 (lower than $2 \%$ of the expression in these cells). The highest expression was found in a nontransgenic MP (up to $10 \%$ of the expression of PERV in PK-15 cells).

\section{PERV expression in different organs of the same animal}

Different organs (brain, heart, lung, liver, spleen, kidney, muscle, and pancreas) from three transgenic animals (GL and GL/MP) as well as five nontransgenic GL animals were analyzed to determine organspecific differences in PERV expression (Fig. 1). Integrity of isolated RNA was confirmed PERV expression in mitogen-treated PBMCs Expression of porcine endogenous retroviruses was measured both in non-stimulated as well as PHAstimulated PBMCs in 32 transgenic and nontransgenic

pigs (Table 7). Previous studies had shown that mitogen stimulation increases the level of PERV expression and that this assay discriminates between PERV low and high producers $[8,9]$. The highest expression was observed in mitogenstimulated PBMCs isolated from non-transgenic MP $(93 \%$ of the expression of PERV in PK-15 cells). All non-transgenic LW animals showed only low level expression after mitogen stimulation (5\%) and were classified as low producer animals. In contrast, expression of PERV in MP/Du/GL and LW/MP/Du animals, transgenic for TNFrelated apoptosis inducing ligand (TRAIL), human decay accelerating factor (hDAF), human leukocyte antigen-E (HLA-E), CD46 and combinations of these transgenes was in the range of $1 \%$ to $8 \%$ of the expression of PERV in PK-15 cells in the case of non-stimulated, and of $1 \%$ to $43 \%$ in the case of stimulated PBMCs. Noteworthy is that these animals had some genetic background of MPs (Table 7). There was no correlation between PERV expression and the presence of PERV-A/C proviruses in these animals, the animals with the highest expression of PERV did not carry PERVA/ C (Table 7).

\section{Absence of virus release}

As PERV expression at the RNA level reached only a small proportion of the expression ofPERVin PK- 15 and 293/50 cells, which release PERV particles, the question arose, whether viral proteins are expressed and whether virus particles were released from these pigs. Different attempts to detect PERV proteins in normal pig tissues have failed so far. The release of particles was observed only in some mitogen-stimulated PBMCs using a RT activity assay (Table 7). PBMCs from animals \#32 $(1.72 \pm 0.11 \mathrm{mU} / \mathrm{ml}), \# 34(2.76 \pm 0.16 \mathrm{mU} / \mathrm{ml})$, and \#28 $(0.75 \pm 0.05 \mathrm{mU} / \mathrm{ml}$, a minipig) released RT activity into the supernatant after stimulation with PHA. No virus release was observed with nonstimulated PBMCs and in most mitogen-stimulated PBMCs. In contrast, RT activities of $12.89 \pm$ $0.20 \mathrm{mU} / \mathrm{ml}$ and $26.12 \pm 0.21 \mathrm{mU} / \mathrm{ml}$, respectively, were found in the supernatant of the cell lines PK-15 and $293 / 50$, respectively. 


\section{Discussion}

Here, we screened a large number of transgenic pigs produced for pre-clinical xenotransplantation research for PERV prevalence and expression. Such careful analyses of animals are required to select only pigs with low or no PERV release to minimize the risk of PERV transmission to the patient. PERV are thought to be an important risk factor when porcine cells, tissues, or organs will be transplanted to human recipients, as PERV-A and PERV-B are present in the genome of all pigs and can infect human cells in vitro [28]. Trans-species transmission of retroviruses is a common phenomenon and was reported for HIV-1, resulting in the pandemic, devastating acquired immunodeficiency syndrome, and retroviruses closely related to PERV [for review see [29]. Importantly, PERV-C is not present in all pigs, thus allowing select PERV-C negative animals. Although PERV-C does not infect human cells, it may represent a risk factor due to putative recombinations between PERV-A and PERV-C. PERV-A/C are humantropic and can adapted to high titers when passaged on human cells in vitro $[17,18]$. As shown in this study, the number of PERV-Cnegative animals was low, but by selection or backcrossing, PERV-C free animals could be generated. The number of PERV-C integrants in existing transgenic pig lines is an important issue that needs to be addressed in future studies. Recombinant PERV-A/C have been observed in DNA of cells from lymphoid tissues of several animals; however, there is clear evidence, that these recombinant viruses were not present in the germ line [16].

Differences in PERV expression correlated with the genetic background of the animals, not with the specific transgene (Tables 6 and 7). MPs had consistently the highest level of PERV expression, and animals with a MP background had a higher level of expression compared with animals without MP background. Theoretically, integration of a transgene in the vicinity of a provirus, an oncogene, a tumor suppressor gene, or any other gene may change the expression of these genes. This may result in a higher expression of PERV in tumor development or dead-born

animals, respectively. The present study included only healthy animals and an elevated PERV expression was not observed in transgenic animals compared with the corresponding nontransgenic animals.

Wild boars were included in this study because a previous report had demonstrated the lack of PERV$\mathrm{C}$ and a lower number of proviruses when compared with domestic pigs [27]. In the present

study, all wild animals carried PERV-C, irrespective of age and the spot. Hunted in places very close to Berlin, these animals may have acquired the virus by contact with breeding animals. As only spleen tissue was investigated, but no other sample, it remains unclear whether PERV-C in these animals is endogenous or exogenous.

Our results confirm previous reports on differences in the expression between different pig breeds as well as between animals within a particular breed $[8,9,30,31]$. The highest expression of PERV was reported in the thymus and lung from MPs [31], and in kidneys and thymus of LW animals [32]. In this study, highest expression was found in the lung from transgenic animals with a GL and MP background (thymus preparations were not available) (FLI Mariensee) (Fig. 1A) and in the spleen of non-transgenic GL animals (LMU Munich) (Fig. 1B). Disseminated or local infections may stimulate PERV expression as activation of retrovirus expression was often described after infections with other viruses [33,34] or Toxoplasma gondii [35]. Such infection may happen in different organs, e.g., in the lung or in the spleen. In addition, both groups lived in different breeding

institutions. The lowest PERV expression was found in pancreatic islet cells throughout all animals (Fig. 1A), confirming previous reports [33,36]. This could facilitate islet cell transplantation for the treatment of diabetes, which is supposed to be the first application of porcine cells [37].

Specific and sensitive assays were developed in the past years to screen for PERV infection, provirus distribution, and PERV expression, at the mRNA level and the protein level as well $[8,9,38]$. Here, these methods were applied to screen systematically for PERV distribution and expression in transgenic pigs generated for xenotransplantation research. Animals expressing hDAF and CD46 to overcome the HAR as well as TRAIL and HLA-E to control the cellular immune responses were analyzed for PERV expression (Table 7). Recently, transgenic pigs were generated expressing a PERV-specific short hairpin RNA, where PERV expression was efficiently inhibited by RNA interference [39]. It is anticipated that multi-transgenic animals will minimize the rejection of pig tissues and decrease the risk of PERV transmission. All these strategies will contribute to an optimized source animal characterized by a low probability of PERV release, absence of HAR, and a reduced cellular rejection [40]. 


\section{References}

1. Petersen B, Carnwath JW, Niemann H. The perspectives for porcine-to-human xenografts. Comp Immunol Microbiol Infect Dis 2008; 32: 91-105.

2. Hammer C. Xenotransplantation-will it bring the solution to organ shortage? Ann Transplant 2004; 9: 7-10.

3. Denner J. Is porcine endogenous retrovirus (PERV) transmission still relevant? Transplant Proc 2008; 40: 587- 589.

4. Patience C, Takeuchi Y, Weiss RA. Infection of human cells by an endogenous retrovirus of pigs. Nat Med 1997; 3: $282-286$.

5. Takeuchi $Y$, Patience $C$, Magre $S$ et al. Host range and interference studies of three classes of pig endogenous retrovirus. $J$ Virol 1998; 72: 9986-9991.

6. Patience C, Switzer WM, Takeuchi Y et al. Multiple groups of novel retroviral genomes in pigs and related species. J Virol 2001; 75: 2771-2775.

7. Martin U, Kiessig $\mathrm{V}$, Blusch $\mathrm{JH}$ et al. Expression of pig endogenous retrovirus by primary porcine endothelial cells and infection of human cells. Lancet 1998; 352: 692- 694.

8. Tacke S, Kurth R, Denner J. Porcine endogenous retrovirus inhibits human immune cells: risk for xenotransplantation. Virol 2000; 268: 87-93.

9. Tacke SJ, Specke V, Denner J. Differences in release and determination of subtype of porcine endogenous retroviruses (PERV) produced by stimulated normal pig blood cells. Intervirology 2003; 46: 17-24.

10. Wilson CA, Wong S, Van Brocklin $\mathrm{M}$ et al. Extended analysis of the in vitro tropism of porcine endogenous retrovirus. J Virol 2000; 74: 49-56.

11. Martin $\mathrm{U}$, Winkler ME, Id $\mathrm{M}$ et al. Productive infection of primary human endothelial cells by pig endogenous retrovirus (PERV). Xenotransplantation 2000; 7: 138-142.

12. Specke $\mathrm{V}$, Rubant $\mathrm{S}$, Denner J. Productive infection of human primary cells and cell lines with porcine endogenous retroviruses. Virol 2001; 285: 177-180.

13. Wood JC, Quinn G, Suling KM et al. Identification of exogenous forms of human-tropic porcine endogenous retrovirus in miniature Swine. J Virol 2000; 78: 2494-2501.

14. Bartosch B, Stefanidis D, Myers R et al. Evidence and consequence of porcine endogenous retrovirus recombination. J Virol 2004; 78: 13880-13890.

15. Martin SI, Wilkinson R, Fishman JA. Genomic presence of recombinant porcine endogenous retrovirusin transmitting miniature swine. Virol J 2006; 3: 91-96.

16. Dieckhoff B, Puhlmann J, Büscher $\mathrm{K}$ et al. Expression of porcine endogenous retroviruses PERVs in melanomas of Munich miniature swine MMS Troll. Vet Microbiol 2007; 123: 53-68.

17. Denner J, Specke V, Thiesen U et al. Genetic alterations of the long terminal repeat of an ecotropic porcine endogenous retrovirus PERV during passage in human cells. Virol 2003; 314: 125-133.

18. Denner J. Recombinant porcine endogenous retroviruses (PERV-A/C): a new risk for xenotransplantation? Arch Virol 2008; 153: 1421-1426.

19. Harrison I, Takeuchi Y, Bartosch B et al. Determinants of high titter in recombinant porcine endogenous retroviruses. J Virol 2004; 78: 13871-13879.

20. Klose R, Kemter E, Bedke T et al. Expression of biologically active human TRAIL in transgenic pigs. Transplantation 2005; 80: $222-223$.

21. Hofmann A, Kessler B, Ewerling S et al. Efficient transgenesis in farm animals by lentiviral vectors. EMBO Rep 2003; 4: $1054-1060$.

22. Besenfelder U, Modl J, Muller M, Brem G. Endoscopic embryo collection and embryo transfer into the oviduct and the uterus of pigs. Theriogenology 1997; 47: 1051-1060.

23. Petersen B, Lucas-Hahn A, Oropeza $M$ et al. Development and validation of a highly efficient protocol of porcine somatic cloning using preovulatory embryo transfer in peripubertal gilts. Cloning Stem Cells 2008; 10: 355-362.

24. Le Tissier P, Stoye JP, Takeuchi Y, Patience C, Weiss RA. Two sets of human-tropic pig retrovirus. Nature 1997; 389: 681682.

25. Duvigneau JC, Hartl RT, Groiss S, Gemeiner M. Quantitative simultaneous multiplex real-time PCR for the detection of porcine cytokines. J Immunol Methods 2005; 306: 16-27.

26. Livak KJ, Schmittgen TD. Analysis of relative gene expression data using real-time quantitative PCR and the 2(-Delta Delta C(T)) method. Methods 2001; 25: 402- 408.

27. Mang R, Maas J, Chen X, Goudsmit J, van Der Kuyl AC. Identification of a novel type C porcine endogenous retrovirus: evidence that copy number of endogenous retroviruses increases during host inbreeding. J Gen Virol 2001; 82: 1829-1834.

28. Denner J. Immunosuppression by retroviruses: implications for xenotransplantation. Ann N Y Acad Sci 1998; 862: 75-86.

29. Denner J. Transspecies transmissions of retroviruses: new cases. Virol 2007; 369: 229-233.

30. Scobie L, Taylor S, Wood JC et al. Absence of replication- competent human-tropic porcine endogenous retroviruses in the germ line DNA of inbred miniature swine. J Virol 2004; 78: 2502-2509.

31. Akiyoshi DE, Denaro M, Zhu H, Greenstein JL, Banerjee P, Fishman JA. Identification of a full-length cDNA for an endogenous retrovirus of miniature swine. J Virol 1998; 72: 4503-4507.

32. Cle'menceau B, Lalain S, Martignat L, Sal" P. Porcine endogenous retroviral mRNAs in pancreas and a panel of tissues from specific pathogen-free pigs. Diabetes Metab 1999; 25: 518-525.

33. Nella ${ }^{\circ}$ ker $\mathrm{C}$, Yao $\mathrm{Y}$, Jones-Brando $\mathrm{L}$, Mallet $\mathrm{F}$, Yolken RH, Karlsson $\mathrm{H}$. Transactivation of elements in the human endogenous retrovirus W family by viral infection. Retrovirology 2006; 3: 44.

34. Ruprecht $\mathrm{K}$, Obojes $\mathrm{K}$, Wengel $\mathrm{V}$ et al. Regulation of human endogenous retrovirus $\mathrm{W}$ protein expression by herpes simplex virus type 1: implications for multiple sclerosis. J Neurovirol 2006; 12: 65-71.

35. Gazzinelli RT, Sher A, Cheever A, Gerstberger S, Martin MA, Dickie P. Infection of human immunodeficiency virus 1 transgenic mice with Toxoplasma gondii stimulates proviral transcription in macrophages in vivo. J Exp Med 1996; 183: 16451655.

36. Irgang M, Laue C, Velten F et al. No evidence for PERV release by islet cells from German landrace pigs. Ann Transplant 2008; 13: 59-66.

37. Schuurman HJ, Pierson RN III. Progress towards clinical xenotransplantation. Front Biosci 2008; 13: 204-220.

38. Tacke S, Bodusch $\mathrm{K}$, Berg A et al. Sensitive and specific immunological detection methods for porcine endogenous retroviruses applicable to experimental and clinical xenotransplantation. Xenotransplantation 2001; 8: 125-135.

39. Dieckhoff $B$, Petersen B, Kues WA et al. Knockdown of porcine endogenous retrovirus (PERV) expression by PERV-specific shRNA in transgenic pigs. Xenotransplantation 2008; 15: 36-45.

40. Sykes M. Progress toward an ideal source animal: opportunities and challenges in a changing world (2007 IXA Presidential Address). Xenotransplantation 2008; 15: 7-13. 
41. Weiss E, Lilienfeld BG, Müller S et al. HLA-E/human 2-microglobulin transgenic pigs: protection against xenogeneic human anti-pig natural killer cell cytotoxicity. Transplantation 2009; 87: 35-43.

42. Kues W, Schwinzer R, Wirth D et al. Epigenetic silencing and tissues independent expression of a novel tetracycline inducible system in double-transgenic pigs. FASEB J 2006; 20: 1200-1202.

\section{Tables and Figures}

Table 1. Production methods of the screened transgenic pigs

\begin{tabular}{|c|c|c|c|c|}
\hline Transgene & Production method & Breed/animals & Animal facility & Reference \\
\hline GI & Lentiviral transgenesis & German Landrace & Munich & [20] \\
\hline TRAIL & Pronuclear DNA microinjection & $\begin{array}{l}\text { German Landrace } \\
\text { Duroc, Berlin Minipig }\end{array}$ & Munich & [19] \\
\hline$H L A \cdot E / \beta 2 m$ & Pronuclear DNA microinjection & $\begin{array}{l}\text { German Landrace } \\
\text { Duroc, Berlin Minipig }\end{array}$ & Munich & [41] \\
\hline $\mathrm{aMHC}$ & Pronuclear DNA microinjection & German Landrace & Munich & a \\
\hline hDAF (hCD55) & Lentiviral transgenesis & $\begin{array}{l}\text { German Landrace } \\
\text { Duroc, Berlin Minipig }\end{array}$ & Munich & $b$ \\
\hline hDAF (hCD55) & Pronuclear DNA microinjection & German Landrace & Mariensee & [42] \\
\hline hCD59 & Pronuclear DNA microinjection & German Landrace & Mariensee & [42] \\
\hline
\end{tabular}

${ }^{a}$ Kemter $E$, Kessler B, Wolf $E$, unpublished data.

bHofmann, A., Kessler, B., Wolf, E., Pfeifer, A., unpublished data.

Table 2. Primer pairs and probes used for polymerase chain reaction (PCR) and real time PCR

\begin{tabular}{|c|c|c|c|}
\hline $\begin{array}{l}\text { Virus gene } \\
\text { detected }\end{array}$ & $\begin{array}{l}\text { Abbreviation, } \\
\text { nt number }\end{array}$ & Sequence & $\begin{array}{c}\text { Reference/ } \\
\text { accession number }\end{array}$ \\
\hline \multirow[t]{4}{*}{ PERV-C } & envC, forward & CTGACCTGGATTAGAACTGG & \multirow[t]{2}{*}{ [4] } \\
\hline & encC, reverse & ATGTTAGAGGATGGTCCTGG & \\
\hline & envC.2, forward: $519-546$ & GATTAGAACTGGAAGCCCCAAGTGCTCT & \multirow[t]{2}{*}{ EU440732 } \\
\hline & env. 2 , reverse: $806-777$ & TCTGATCCAGAAGTTATGTIAGAGGATGGT & \\
\hline \multirow[t]{3}{*}{ PERV-A/C } & PERV-A env VRBF, forward & CCTACCAGT TATAATCAATTTAATTATGGC & \multirow[t]{3}{*}{ [12] } \\
\hline & PERV-C env TMR & CTCAAACCACCCTTGAGTAGTTCC & \\
\hline & PEFV-C, reverse & TATGTTAGAGGATGGTCCTGGTC & \\
\hline \multirow[t]{3}{*}{ PEFN gag } & Forward & TCCAGGGCTCATAATTTGTC & \multirow[t]{3}{*}{ [36] } \\
\hline & Reverse & TGATGGCCATCCAACATCGA & \\
\hline & Probe & FAM-AGAAGGGACCTTGGCAGACTTTCT-BHQ1 & \\
\hline \multirow{3}{*}{$\begin{array}{l}\text { PEFV-C } \\
\text { real time }\end{array}$} & PEFV-C, forward: $480-500$ & СACCTATACCAGCT CTGGACA & \multirow[t]{3}{*}{ EU440732 } \\
\hline & PERV-C, reverse: $791-772$ & ATGTTAGAGGATGGTCCTGG & \\
\hline & Probe $509-533$ & HEX-ACCTGACCTGGATTAGAACTGGAAG-BHO1 & \\
\hline \multirow[t]{3}{*}{ GAPDH } & Forward & ACATGGCCTCCAAGGAGTAAGA & a \\
\hline & Reverse & GATCGAGTTGGGGCTGTGACT & a \\
\hline & Probe & HEX-CCACCAACCCCAGCAAGAGCACGC-BHO1 & a \\
\hline \multirow[t]{3}{*}{ HPRT } & Forward & GTGATAGATCCATTCCTATGACTGTAGA & a \\
\hline & Reverse & TGAGAGATCATCTCCACCAATTACTT & a \\
\hline & Probe & FAM-AT CGCCCGTTGACTGGTCATTACAGTAGCT-BHQ1 & $11 a$ \\
\hline
\end{tabular}

aperon, Cologne, Germany. 
Table 3. Presence of PERV-C in pigs of different breeds

\begin{tabular}{|c|c|c|c|c|}
\hline Breed/crossbreed & Transgene & $\begin{array}{l}\text { DNA } \\
\text { isolated } \\
\text { from }\end{array}$ & $\begin{array}{l}\text { Number } \\
\text { tested }\end{array}$ & $\begin{array}{c}\text { Number } \\
\text { of PERV-C } \\
\text { negative }\end{array}$ \\
\hline \multirow{5}{*}{ German Landrace (GL) } & None & PBMCs & 19 & 1 \\
\hline & GIP & Ear biopsy & 1 & 0 \\
\hline & HLA.E & Ear biopsy & 5 & 0 \\
\hline & TRAIL & Ear biopsy & 4 & 0 \\
\hline & $\alpha-\mathrm{MHC}$ & Ear biopsy & 1 & 0 \\
\hline Duroc (Du) & None & PBMCs & 12 & 0 \\
\hline Mini-pig (MP) & None & PBMCs & 1 & 0 \\
\hline Large White (LW) & None & PBMCs & 3 & 0 \\
\hline $\mathrm{Du} / \mathrm{GL}$ & None & Ear biopsy & 22 & 0 \\
\hline Schwabisch-Hallisch (SH) & None & PBMCs & 10 & 0 \\
\hline \multirow[t]{3}{*}{ GL/Pietrain } & HLA.E & Ear biopsy & 1 & 0 \\
\hline & $\mathrm{hDAF}$ & Ear biopsy & 1 & 0 \\
\hline & Lenti DAF & Ear biopsy & 5 & 2 \\
\hline \multirow[t]{4}{*}{ GL/Du } & TRAIL & Ear biopsy & 4 & 0 \\
\hline & TRAIL, HLAE & Ear biopsy & 3 & 0 \\
\hline & HLA.E & Ear biopsy & 2 & 0 \\
\hline & hDAF & Ear biopsy & 1 & 0 \\
\hline $\mathrm{Du} / \mathrm{MP}$ & TRAIL & Ear biopsy & 2 & 0 \\
\hline \multirow[t]{5}{*}{ LW/Du/MP } & TRAIL, hDAF & PBMCs & 18 & 0 \\
\hline & TRAIL, HLA-E, hDAF & PBMCs & 6 & 0 \\
\hline & HLA.E, hDAF & PBMCs & 5 & 0 \\
\hline & TRAIL & PBMCs & 2 & 0 \\
\hline & hDAF & PBMCs & 14 & 0 \\
\hline \multirow[t]{6}{*}{ GL/MP/Du } & TRAIL, HLAE & Ear biopsy & 7 & 0 \\
\hline & TRAIL, hDAF & Ear biopsy & 1 & 0 \\
\hline & HLA-E & Ear biopsy & 3 & 0 \\
\hline & HLA-E, hDAF & Ear biopsy & 1 & 0 \\
\hline & TRAIL & Ear biopsy & 1 & 0 \\
\hline & $\mathrm{hDAF}$ & Ear biopsy & 1 & 0 \\
\hline GL/Pietrain & hDAF & PBMCs & 1 & 1 \\
\hline \multirow[t]{2}{*}{ LW/MP/Du/GL } & TRAIL, hDAF & PBMCs & 3 & 1 \\
\hline & $\mathrm{hDAF}$ & PBMCs & 3 & 0 \\
\hline Wild boar & None & Spleen cells & 18 & 0 \\
\hline Total & & & 181 & 5 \\
\hline Total non-transgenic & & & 85 & 1 \\
\hline Total transgenic & & & 96 & 4 \\
\hline
\end{tabular}

PBMCs, peripheral blood mononuclear cells; PEAV, porcine endogeneous retrovirus. PEFV-A and PEFN-B were found in all animals. 
Table 4. Presence of PERV-C and PERV-A/C in wild boars

\begin{tabular}{rcclccc}
\hline No. & Location $^{a}$ & Age (yr) & Gender & Weight (kg) & PERN-C & PEFN-A/C \\
\hline 1 & A & $1-2$ & Female & 50 & + & - \\
2 & A & $1-2$ & Female & 50 & + & - \\
3 & A & $<1$ & Male & 18 & + & - \\
4 & A & $<1$ & Male & 20 & + & - \\
5 & A & $<1$ & Male & 24 & + & - \\
6 & A & $<1$ & Male & 23 & + & - \\
7 & B & $<1$ & Female & 15 & + & - \\
8 & C & $1-2$ & Female & 55 & + & - \\
9 & C & $1-2$ & Female & 55 & + & - \\
10 & C & $1-2$ & Male & 45 & + & - \\
11 & C & $>2$ & Female & 65 & + & - \\
12 & C & $<1$ & Female & 15 & + & - \\
13 & D & $<1$ & Female & 15 & + & - \\
14 & D & $1-2$ & Male & 45 & + & - \\
15 & D & $1-2$ & Male & 50 & + & - \\
16 & D & $1-2$ & Male & 55 & + & - \\
17 & D & $<1$ & Female & 25 & + & - \\
18 & D & $>2$ & Female & 70 & + & - \\
\hline
\end{tabular}

PERV, porcine endogeneous retrovirus.

aA, B, C, D indicate four different locations near Berlin.

bPERV-A and PERV-B were found in all animals.

Table 5. Detection of PERV-A/C in pigs of different breeds

\begin{tabular}{|c|c|c|c|c|}
\hline Breed/Crossbreed & Transgene & $\begin{array}{l}\text { DNA isolated } \\
\text { from }\end{array}$ & $\begin{array}{l}\text { Number } \\
\text { tested }\end{array}$ & $\begin{array}{c}\text { Number of } \\
\text { PERV-A/C positive }\end{array}$ \\
\hline Mini-pig (MP) & None & PBMCs & 1 & 0 \\
\hline Large White (LW) & None & PBMCs & 3 & 0 \\
\hline \multirow[t]{8}{*}{ LW/MP/Du } & TRAIL, hDAF & Ear biopsy & 6 & 0 \\
\hline & & PBMCs & 6 & 3 \\
\hline & TRAIL, HLA-E, hDAF & PBMCs & 5 & 4 \\
\hline & HLA.E, hDAF & PBMCs & 4 & 2 \\
\hline & TRAIL & Ear biopsy & 1 & 0 \\
\hline & & PBMCs & 1 & 0 \\
\hline & hDAF & PBMCs & 12 & 6 \\
\hline & & Ear biopsy & 2 & 0 \\
\hline \multirow[t]{2}{*}{ LW/MP/Du/GL } & TRAIL, hDAF & PBMCs & 2 & 1 \\
\hline & hDAF & PBMCs & 3 & 2 \\
\hline Wild boar & None & Spleen cells & 18 & 0 \\
\hline Total & & & 64 & 18 \\
\hline Total non-transger & & & 22 & 0 \\
\hline
\end{tabular}

PERV, porcine endogeneous retrovirus; PBMCs, peripheral blood mononuclear cells; Du, Duroc; GL, German Landrace. 
Table 6. Expression of PERV RNA in PBMCs of different non-transgenic Pigs

\begin{tabular}{rcc}
\hline No. & Breed/crossbreed & \% PERV expression of PK-15 \\
\hline 1 & Du/GL & $0.23 \pm 0.06$ \\
2 & Du/GL & $0.53 \pm 0.15$ \\
3 & Du/GL & $0.14 \pm 0.15$ \\
4 & Du/GL & $0.21 \pm 0.06$ \\
5 & Du/GL & $0.28 \pm 0.08$ \\
6 & Du/GL & $0.30 \pm 0.09$ \\
7 & Du/GL & $0.47 \pm 0.13$ \\
8 & Du/GL & $0.16 \pm 0.04$ \\
9 & Du/GL & $0.22 \pm 0.07$ \\
10 & Du/GL & $0.23 \pm 0.06$ \\
11 & GL & $0.17 \pm 0.05$ \\
12 & GL & $1.21 \pm 0.33$ \\
13 & GL & $0.38 \pm 0.10$ \\
14 & GL & $0.39 \pm 0.10$ \\
15 & GL & $0.26 \pm 0.07$ \\
16 & GL & $0.26 \pm 0.07$ \\
17 & GL & $0.31 \pm 0.08$ \\
18 & GL & $0.21 \pm 0.03$ \\
19 & $\mathrm{SH}$ & $0.69 \pm 0.19$ \\
20 & SH & $0.70 \pm 0.19$ \\
21 & $\mathrm{SH}$ & $0.16 \pm 0.04$ \\
22 & $\mathrm{SH}$ & $1.00 \pm 0.31$ \\
23 & $\mathrm{SH}$ & $1.07 \pm 0.30$ \\
24 & $\mathrm{SH}$ & $2.09 \pm 0.57$ \\
25 & $\mathrm{SH}$ & $0.62 \pm 0.17$ \\
26 & $\mathrm{SH}$ & $0.98 \pm 0.27$ \\
27 & $\mathrm{SH}$ & $0.22 \pm 0.06$ \\
28 & $\mathrm{MP}$ & $10.48 \pm 5.28$ \\
29 & $\mathrm{LW}$ & $3.72 \pm 1.37$ \\
30 & $\mathrm{LW}$ & $0.17 \pm 0.09$ \\
31 & $\mathrm{LW}$ & $5.32 \pm 2.01$ \\
\hline
\end{tabular}

MP, minipig; SH, Schwabisch-Hallisch; GL, German Landrace; LW, Large White; Du, Duroc; PBMC, peripheral blood mononuclear cell; PERV, porcine endogeneous retrovirus.

Animals in one group always represent one litter. 
Table 7. Expression of PERV in pig PBMCs before and after mitogen stimulation

\begin{tabular}{|c|c|c|c|c|c|c|c|}
\hline \multirow[b]{2}{*}{ №. } & \multirow[b]{2}{*}{ Breed/crossbreed } & \multirow[b]{2}{*}{ PERV-A/C } & \multirow[b]{2}{*}{ Transgene } & \multicolumn{2}{|c|}{$\%$ Expression of PK-15 } & \multicolumn{2}{|c|}{ RT activity } \\
\hline & & & & Non-stimulated & PHA-stimulated & Non-stimulated & PHA-stimulated \\
\hline 32 & MP/Du/GL & - & TRAIL, hDAF & $4.79 \pm 1.3$ & $6.07 \pm 1.67$ & 0 & $1.72 \pm 0.11$ \\
\hline 33 & MP/Du/GL & - & HLA.E & $1.49 \pm 0.46$ & $2.19 \pm 0.72$ & 0 & 0 \\
\hline 34 & MP/Du/GL & - & HLA.E & $3.91 \pm 1.10$ & $5.12 \pm 1.39$ & 0 & $2.76 \pm 0.16$ \\
\hline 35 & LW/MP/Du & + & hDAF & $1.69 \pm 0.46$ & $6.45 \pm 1.85$ & 0 & 0 \\
\hline 36 & LW/MP/Du & + & hDAF & $1.84 \pm 0.53$ & $7.69 \pm 2.40$ & 0 & 0 \\
\hline 37 & LW/MP/Du & + & hDAF & $1.42 \pm 0.40$ & $2.53 \pm 0.89$ & 0 & 0 \\
\hline 38 & LW/MP/Du & + & TRAIL, hDAF & $2.95 \pm 0.81$ & $6.09 \pm 2.16$ & 0 & 0 \\
\hline 39 & LW/MP/Du & + & TRAIL, hDAF & $6.94 \pm 1.88$ & $7.68 \pm 2.61$ & 0 & 0 \\
\hline 40 & LW/MP/Du & - & hDAF & $0.93 \pm 0.30$ & $1.24 \pm 0.36$ & 0 & 0 \\
\hline 41 & LW/MP/Du & - & TRAIL, hDAF & $1.32 \pm 0.37$ & $8.79 \pm 2.96$ & 0 & 0 \\
\hline 42 & LW/MP/Du & + & hDAF & $0.63 \pm 0.19$ & $1.77 \pm 0.51$ & 0 & 0 \\
\hline 43 & LW/MP/Du & + & $\mathrm{hDAF}$ & $2.69 \pm 0.73$ & $15.02 \pm 4.53$ & 0 & 0 \\
\hline 44 & $\mathrm{LW} / \mathrm{MP} / \mathrm{Du}$ & - & HLA.E, hDAF & $1.53 \pm 0.41$ & $8.61 \pm 2.34$ & 0 & 0 \\
\hline 45 & LW/MP/Du & - & HLA.E, hDAF & $1.16 \pm 0.32$ & $2.77 \pm 0.76$ & 0 & 0 \\
\hline 46 & LW/MP/Du & + & hDAF & $4.02 \pm 1.09$ & $2.75 \pm 0.75$ & 0 & 0 \\
\hline 47 & LW/MP/Du & + & HLA.E, hDAF & $2.14 \pm 0.58$ & $12.13 \pm 3.29$ & 0 & 0 \\
\hline 48 & LW/MP/Du & - & hDAF & $3.33 \pm 0.97$ & $7.04 \pm 1.91$ & 0 & 0 \\
\hline 49 & LW/MP/Du & + & TRAIL, HLA-E, hDAF & $3.40 \pm 0.92$ & $5.03 \pm 1.38$ & 0 & 0 \\
\hline 50 & LW/MP/Du & - & TRAIL, HLA-E, hDAF & $2.20 \pm 0.60$ & $3.02 \pm 0.83$ & 0 & 0 \\
\hline 51 & LW/MP/Du & + & TRAIL, HLA-E, hDAF & $2.25 \pm 0.62$ & $3.44 \pm 0.93$ & 0 & 0 \\
\hline 52 & LW/MP/Du & + & HLAE, hDAF & $1.23 \pm 0.33$ & $2.55 \pm 0.69$ & 0 & 0 \\
\hline 53 & LW/MP/Du & + & TRAIL, HLA-E, hDAF & $1.50 \pm 0.41$ & $5.23 \pm 1.47$ & 0 & 0 \\
\hline 54 & LW/MP/Du & - & TRAIL, HLA-E & $3.54 \pm 1.12$ & $37.20 \pm 10.96$ & 0 & 0 \\
\hline 55 & LW/MP/Du & - & TRAIL, HLA-E & $6.00 \pm 1.63$ & $13.23 \pm 3.86$ & 0 & 0 \\
\hline 56 & LW/MP/Du & - & TRAIL, HLA-E & $8.19 \pm 2.82$ & $43.90 \pm 12.01$ & 0 & 0 \\
\hline 57 & LW/MP/Du & - & TRAIL & $0.74 \pm 0.21$ & $39.45 \pm 10.94$ & 0 & 0 \\
\hline 58 & LW/MP/Du & - & TRAIL, hDAF & $4.54 \pm 1.71$ & $18.31 \pm 5.60$ & 0 & 0 \\
\hline 59 & MP/Du/GL & - & HLA-E, CD46 & $2.67 \pm 0.83$ & $11.09 \pm 3.22$ & 0 & 0 \\
\hline 28 & MP & - & - & $10.48 \pm 5.28$ & $92.58 \pm 25.85$ & 0 & $0.75 \pm 0.05$ \\
\hline 29 & LW & - & - & $3.72 \pm 1.37$ & $4.21 \pm 1.33$ & 0 & 0 \\
\hline 30 & LW & - & - & $0.17 \pm 0.09$ & $5.02 \pm 1.38$ & 0 & 0 \\
\hline 31 & $L W$ & - & - & $5.32 \pm 2.01$ & $5.42 \pm 1.99$ & 0 & 0 \\
\hline PK-15 & - & - & - & $100.00 \pm 8.41$ & & $12.89 \pm 0.20$ & \\
\hline $293 / 50$ & - & - & - & $628.95 \pm 32.74$ & & $26.12 \pm 0.21$ & \\
\hline
\end{tabular}

MP, Mini-pig; SH, Schwabisch-Hallisch; GL, German Landrace; LW, Large White; Du, Duroc; PBMC, peripheral blood mononuclear cells; PERV, porcine end ogeneous retrovirus; RT, reverse transcriptase; PHA, phytohemagglutinin.

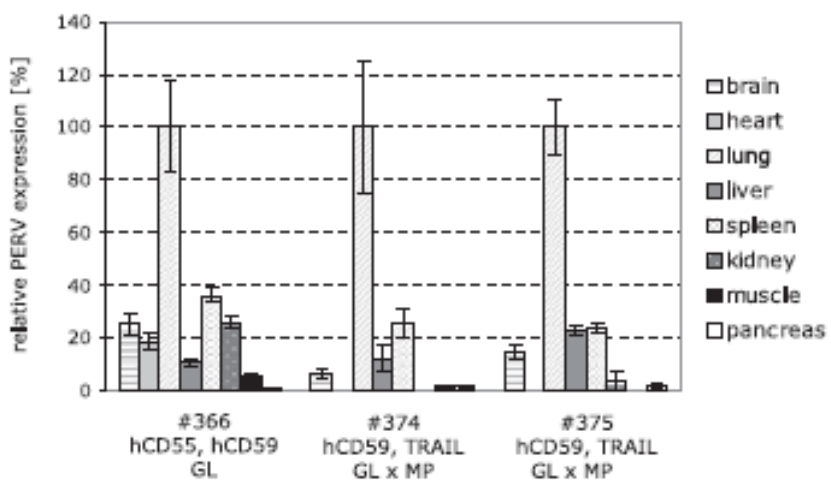

Fig. 1. (A) Expression of porcine endogenous retroviruses (PERV) in different tissues of multi-transgenic (TRAIL, CD55, CD59) German landrace (GL) pigs (\#366) and GL pig · mini-pig (MP) animals (\#374, \#375) as measured by real time polymerase chain reaction. Expression in the lung was set $100 \%$. (B) Expression of PERV in different tissues of fivedifferent non-transgenic GL pigs (1--5), expression in the spleen was set $100 \%$.

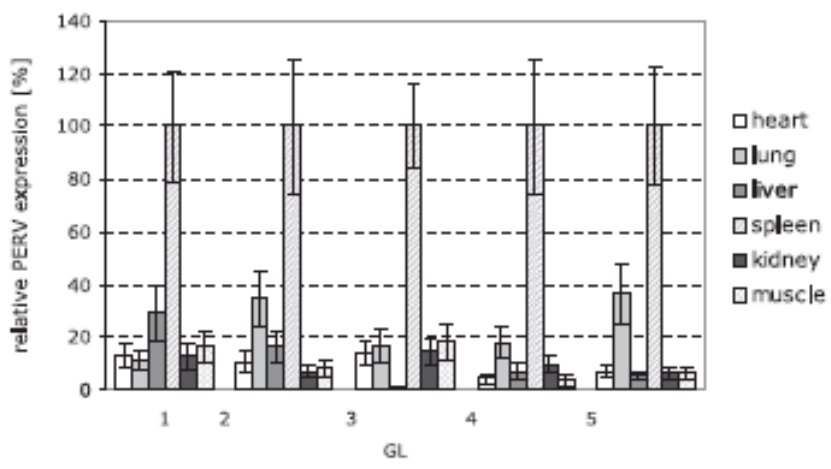

